\title{
Comparison of Gait Stability of using an Outdoor Rollator with Walking and using a Bassinet as Ambulatory Aid
}

\author{
Min Su Park ${ }^{1}$, Soo Hee Park', Yeong Ae Yang ${ }^{3,4}$ \\ ${ }^{1}$ Department of Occupational Therapy, Graduate School of Inje University, Gimhae, 621-749 \\ ${ }^{2}$ Department of Occupational Therapy, Honam University, Gwangju, 516-714 \\ ${ }^{3}$ Department of Occupational Therapy, College of Biomedical Sciences and Engineering, \\ Inje University, Gimhae, 621-749 \\ ${ }^{4}$ Institute of Aged Life Redesign, Inje University, Gimhae, 621-749
}

\begin{abstract}
Objective: The purpose of this study is to find the problems of stability when people use the bassinet as an ambulatory aid for old people. Background: Many aged people use a bassinet as ambulatory aid. But the safety of using the bassinet as ambulatory aid has not been verified yet. Method: The 13 university-students who don't have musculoskeletal disorders volunteered to participate in this study. According to structural analysis of the both tools, we compared the structural stability of an outdoor rollator with the structural stability of a bassinet. And when the participants walked using both tools, the motions were captured and analysed. We measured the angle of shoulder joint and the angle of trunk from the ground when the participants were walking. And we found the distance from participants' pressure cone apex and greater trochanter. Results: Following the structural analysis, the bassinet has the lower structural stability than the outdoor rollator. When the people used the bassinet as ambulatory aid, the angle of the shoulder joint was bigger than to use the outdoor rollator. The angle of trunk wasn't different between the outdoor rollator and the bassinet. And distance from pressure cone apex to greater trochanter was far to use the bassinet than to use the outdoor rollator. Conclusion: Through the structure analysis and gait analysis of the bassinet and the outdoor rollator, we can be aware of that the bassinet has problem of stability. Therefore the people who use the bassinet as an ambulatory aid, especially supporting body weight, may be hurt due to the problems of stability. Application: This research can be used for developing a study of the ambulatory aid and preventing the accident when the aged people use the ambulatory aid.
\end{abstract}

Keywords: Ambulatory aid, Outdoor rollator, Bassinet, Stability, Gait analysis

\section{Introduction}

통계청이 발표한 '2008 고령자 통계'에 따르면 2008년 7월 1일 현재 65세 이상 노인 인구는 501만 6000명으로 총인구의 $10.3 \%$ 를 차지했다. 지난 2000 년 노인인구 비율
이 $7.2 \%$ 로 고령화 사회에 진입한 우리나라는 이 같은 추세 가 이어질 경우 2018 년에는 노인인구 비율이 $14.3 \%$ 로 고 령사회, 2026년에는 $20.8 \%$ 로 초고령 사회에 진입할 것으로 전망된다(Statistics Korea, 2008). 이는 2005년에 비해 $0.4 \%, 10$ 년 전과 비교하면 $3.4 \%$ 나 높아진 것이다. 노인이 늘고 출산율이 급락하면서 10 년 전에는 생산 가능 인구

Corresponding Author: Yeong Ae Yang. Department of Occupational Therapy, College of Biomedical Science and Engineering, Inje University, Gimhae, $621-749$. Mobile: 010-7227-6853, E-mail: otyya62@inje.ac.kr Copyright@2012 by Ergonomics Society of Korea(pISSN:1229-1684 eISSN:2093-8462). All right reserved.

(c) This is an open-access article distributed under the terms of the Creative Commons Attribution Non-Commercial License(http://creativecommons.org/licenses/by-nc/3.0/), which permits unrestricted non-commercial use, distribution, and reproduction in any medium, provided the original work is properly cited. 
11.6명당 1 명의 노인을 부양해야 했으나 2008년에는 7.6명 이 그 역할을 해야 하는 것으로 분석됐다(Cho, 2008).

노인이 되면 신체적으로 탈모, 백발, 노쇠현상, 치아탈락, 척추연골 위축과 같은 외관상의 변화와 소화기, 심장, 뇌의 위축 및 그 기능상의 변화 등 해부적인 변화가 나타난다 (Yang, et al., 2008). 또한 연령이 증가함에 따라 체력 손실 과 더불어 감각 기능이 현저하게 저하되고, 자세 유지에 관 여하는 중추신경계의 기능이 감퇴하여 평형능력이 저하된다 (Kauffman, 1999; Spirduso, et al., 2005). 뿐만 아니라 노 인의 하지 근력은 유의하게 감소되어(Lewis and Bottomley, 2002), 80대의 노인은 30대의 성인에 비해 하지의 근력이 $40 \%$ 나 감소하게 된다는 연구도 있다(Anniansson, et al., 1986). 이러한 원인으로 많은 노인에게서 낙상 및 보행능 력의 상실이 발생하며, 이는 노인의 일상생활 동작 독립성 저하의 가장 심각한 원인 중의 하나가 된다(Guralink and Kaplan, 1989).

이러한 보행능력의 상실을 보상하기 위해 노인을 위한 다 양한 종류의 보행보조도구들이 사용되고 있다. 일본의 사단 법인복지용구협회(Association for Technical Aids)에서는 보행과 관련된 보장구 제품을 크게 이동기기로 분류하여 이 를 개인의 이동을 목적으로 하여 사용하는 개인용의 이동기 기라고 정의하고 있다. 즉 기능이 저하되어 일상생활을 영위 하는데 지장이 있는 노인의 거동을 돕는 복지용구라고 할 수 있으며, 이에 해당되는 품목은 지팡이나 보행기, 보행차 및 휠체어 등으로 크게 분류된다(Hwang, 2006). 이러한 보행 보조도구를 사용함에 따라 얻는 이득에는 지지 기저면의 확 장을 통한 안정성의 증대, 저하된 균형능력에 대한 보상 및 체중보조 등이 있다(Smidt and Mommens, 1980).

특히 자립 보행이 가능한 노인이 옥외에서 보행을 위해 사 용하는 4 륜 방식의 보행보조도구를 보행보조차라 하며, 일반 적으로 보행보조차는 핸들, 프레임, 스톱퍼로 구성되어 있어 노인이 외출할 때 보행이나 물건의 운반 및 휴식에 사용한다 (Korea Agency for Technology and Standards, 2007). 보행보조차와 여타 보행보조도구와의 가장 큰 차이점은 보 행에 있어 사용자의 재활훈련이나 자립의 목적이 아닌 보 행 안정 및 이동거리의 연장에 그 목적이 있다는 것이다 (Hwang, 2006). 이러한 목적에 맞추어 보행보조차는 사용 자의 체중지지와 보행 거리 및 보행의 질 향상을 위해 디자 인되었고, 다른 보행보조도구와 비교할 때 옥외에서의 사용 에 매우 편리하다(Finkel, et al., 1997).

보행능력이 저하된 노인의 경우, 보행보조차에 대한 사용 만족도가 높은 편이어서 Samuelsson and Wressle(2008) 의 연구를 살펴보면, 262 명의 보행보조차 사용자들에 대한 만족도 조사에서 대부분의 이용자들이 재활 치료 이후 보행 보조차를 사용하는 것이 매우 유용하고 효과가 있다는 진술
을 하였다. 또한 보행보조차가 노인의 사회활동 및 사회적 소통에 있어 유용하다는 연구도 있다(Brandt, et al., 2003).

하지만 보행보조차가 필요함에도 불구하고 비용적 측면 및 보행보조차에 대한 인식 부족으로 인해 보행보조차 대용 으로 유모차를 사용하는 노인들이 있다(Lee, 2007). 또한 일부 지역 보건소 및 읍, 면, 동 주민자치센터에서는 지역 주 민들에게 유모차를 수거하여 노인들에게 보급하는 지역 사업 을 시행하기도 한다(Kim, 2007; Jung, 2006; Eom, 2005). 하지만 유모차를 아동의 이동이 아닌 노인의 보행보조도구 로 사용할 때, 유모차의 구조적 상이함으로 인한 안정성의 문제가 발생할 수 있다고 연구되고 있다(Park and Cho, 2008).

이에 따라 본 연구에서는 다음을 통해 보행보조차의 안정 성을 측정하고자 한다.

첫째, 보행보조차와 유모차의 구조분석을 통해 최대 하중 을 산출한다.

둘째, 보행보조차와 유모차를 이용한 보행 시 견관절 각도 를 측정 및 분석한다.

셋째, 보행보조차와 유모차를 이용한 보행 시 지면에 대한 체간의 각도를 측정 및 분석한다.

넷째, 보행보조차와 유모차를 이용한 보행 시 힘의 작용점 에서부터 대전자까지 거리를 측정 및 분석한다.

\section{Method}

\subsection{Subjects}

본 연구는 경남 소재 $\mathrm{OO}$ 대학교에 재학 중인 20 대 남, 여 총 13 명 (남자 6 명, 여자 7 명)을 대상으로 하였다. 이들은 본 연구에 대한 설명을 듣고 자발적으로 연구에 참여할 것을 동의한 자로, 최근 1 년 내에 근골격계 관련 외상이나 질환이 없었고, Berg Balance Scale(BBS: 이하 BBS) 52점 이상 획득한 자였다.

\subsubsection{General information}

본 연구에 참여한 대상자의 나이는 남자의 경우 평균 24.6 세 여자의 경우 평균 21.5세이다. 신장은 남자의 경우 평균 $172.60 \mathrm{~cm}$ 이고, 여자의 경우 평균 $164.75 \mathrm{~cm}$ 이다. 체 중은 남자의 경우 평균 $71.0 \mathrm{~kg}$ 여자의 경우 평균 $57.9 \mathrm{~kg}$ 이 다. $\mathrm{BBS}$ 평가 결과는 총점 56점에 피실험자 모두 56점으로 낙상의 위험이 없었다(Table 1). 
Table 1. General information

\begin{tabular}{c|c|c}
\hline & Man(n=6) & Women $(\mathrm{n}=7)$ \\
\hline Age & $24.60 \pm 0.55$ & $21.50 \pm 2.45$ \\
\hline Height $(\mathrm{cm})$ & $172.60 \pm 4.28$ & $164.75 \pm 8.22$ \\
\hline Weight $(\mathrm{kg})$ & $71.00 \pm 8.60$ & $57.88 \pm 13.20$ \\
\hline BBS & 56 & 56 \\
\hline
\end{tabular}

\subsection{Equipments}

\subsubsection{Outdoor rollator}

본 연구에 사용된 보행보조차는 (주) 대세엠케어의 U자형 롤레이터 제품이 사용되었다. 이 장비의 구체적인 제원은 높 이 $86.9 \mathrm{~cm}$, 축간거리 $53.2 \mathrm{~cm}$, 바퀴간거리(뒷바퀴) $50.6 \mathrm{~cm}$, 무게 $10.5 \mathrm{~kg}$ 이다(Figure 1).

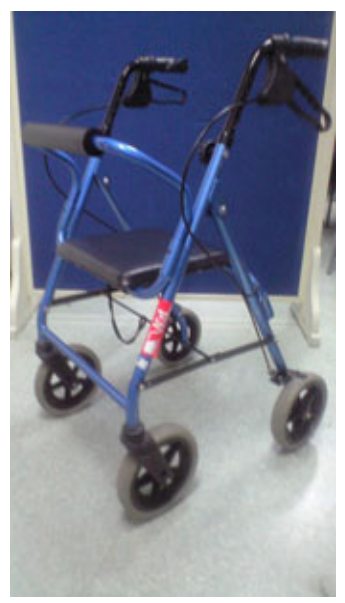

Figure 1. Outdoor rollator

\subsubsection{Bassinet}

본 연구에 사용된 유모차는 (주)해피랜드의 S-801 HL (맥스 유모차) 제품이 사용되었다. 이 장비의 구체적인 제원 은 높이 $91.2 \mathrm{~cm}$, 축간거리 $61.8 \mathrm{~cm}$, 바퀴간거리(뒷바퀴) $57.8 \mathrm{~cm}$, 무게 $10.1 \mathrm{~kg}$ 이다(Figure 2).

\subsubsection{Berg balance scale(BBS)}

연구의 대상자 선별 시 사용된 평가 도구로써 평형능력을 측정하는 측정 도구이다. 14 개의 항목으로 구성되어 있으며 크게 앉기, 서기, 자세 변화의 3가지 영역으로 나눈다. 최소 0점에서 최고 4점의 5점 척도로 구성되어 있고 총점은 56 점이다. 이 평가 도구의 검사자 간 신뢰도 계수는 0.98이고, 피검사자 내 신뢰도 계수는 0.97이다(Berg, et al., 1995).

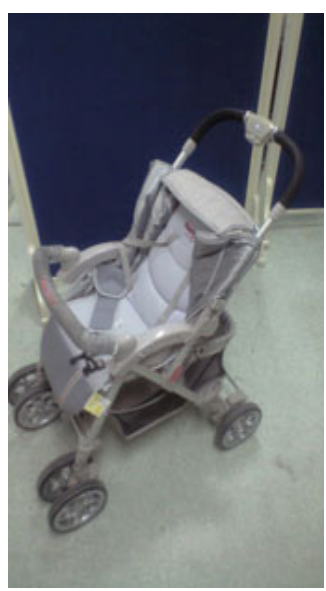

Figure 2. Bassinet

Berg, et al. (1992)는 45점 이하의 점수를 받은 사람은 낙 상 위험성이 높다고 하였다.

\subsection{Procedure}

개괄적인 연구과정은 아래와 같다. 먼저 연구대상자 및 연 구 도구를 선정하였다. 이후 보행보조차와 유모차에 대한 구 조분석을 실시하였고, 보행보조차와 유모차에 대한 보행분석 을 시행하였다. 보행분석을 통해 견관절 각도, 지면에 대한 체간의 각도, 힘의 작용점과 대전자 사이의 거리를 측정하고, 이 측정값을 분석하여 결과를 도출하였다.

\subsubsection{Structure analysis of the outdoor rollator and the bassinet}

보행보조차와 유모차의 무게와 각 프레임의 길이 및 프레 임간 각도를 측정하여 손잡이에 수직힘이 가해졌을 때, 구조 물이 구조안정성을 유지할 수 있는 최대 하중의 크기를 측정 하였다. 줄자와 각도계를 이용해 각 보행보조도구의 프레임 길이와 각을 측정하고, 구조역학 분석을 통해 최대 하중을 측정하였다. 이후 유한 요소 구조해석 프로그램인 Abaqus 를 이용한 시물레이션 처리를 통해 측정한 값을 검증하였다.

\subsubsection{Research environment and control variable}

본 연구는 가로 $6 \mathrm{~m}$, 세로 $15 \mathrm{~m}$ 인 시멘트 바닥의 평평하 고 밝은 실내에서 실시하였다. 실험실 바닥에 피실험자들의 이동경로를 $3 \mathrm{~m}$ 의 직선의 테이프로 표시하였다. 피실험자의 보행을 촬영하기 위해 피실험자의 이동경로에서 수평 방향 으로 $3 \mathrm{~m}$ 떨어진 지점에 이동식 측정레일을 설치하고, 이동 식 측정레일에는 피실험자를 촬영하기 위한 $30 \mathrm{frame} / \mathrm{sec}$ 의 디지털카메라를 설치하였다. 실험과정 동안 피실험자의 보 
행 방향과 카메라의 촬영 각도가 수직상태를 유지하기 위해 정렬용 레이저 포인터를 카메라에 부착하였다.

유모차의 손잡이 높이가 조절이 되지 않아 보행보조차의 손잡이 높이와 유모차 손잡이 높이를 동일하게 맞추어 고정 하였고, 피실험자의 잡기자세를 통제하기 위해 전완의 중립 위를 유지한 채 자연스럽게 손잡이를 잡도록 지시하였다. 피 실험자에 대한 일반적 정보 파악 및 실험 적격자의 선별을 위해서 키와 몸무게 측정 및 $\mathrm{BBS}$ 평가를 실시하였다. 이후 피실험자의 신체분절 각도 변화를 측정하기 위해, 피실험자 의 좌측 견봉돌기(acromion), 좌측 주관절 외측상과(lateral epicondyle), 좌측 대전자(great trochanter), 좌측 슬관절 (knee Joint)에 지름 $3 \mathrm{~cm}$ 의 원형 표식자를 부착하였다.

\subsubsection{Design of experiment}

촬영 전 피실험자가 보행보조차와 유모차를 이용한 체중 지지 보행에 익숙해지도록, 각각 1 분 간의 연습시간을 제공 하였다. 연습시간 동안 자유롭게 체중지지 보행을 연습할 수 있도록 지도하였다. 피실험자들은 미리 표시된 직선의 이동 경로를 따라 보행보조차와 유모차에 체중지지를 한 상태로 보행하였다(Figure 3) (Figure 4). 촬영은 피실험자가 출발 지점에서 보행을 시작한 순간부터, 출발지점의 $3 \mathrm{~m}$ 전방에 설치한 종료구간을 피실험자의 신체가 모두 통과할 때까지 진행하였다. 보행시 시선의 분산으로 인한 척추 각도 및 균 형의 변화를 통제하기 위해, 이동경로의 종료지점에 피실험 자의 눈높이에 맞춘 원형 응시점을 부착하여, 피실험자가 보 행을 하는 동안 응시점을 주시하도록 지시하였다.

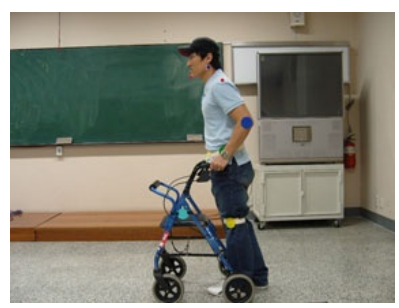

Figure 3. Outdoor rollator

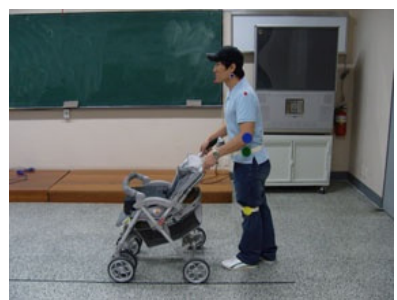

Figure 4. Bassinet

\subsubsection{Result interpretation}

촬영된 동영상을 확인할 수 있는 KMPlayer를 이용하여 촬영 결과를 1 차 확인하였고, 동영상자료를 분할된 사진자 료로 변환할 수 있는 프로그램인 VirtualDub을 이용하여 동영상을 보행 cycle에 따라 정지된 사진자료로 변환하였다. 이후 사진자료 내 특정 관절 등의 각도를 분석할 수 있는 SiliconCoach Pro7을 사용하여 각 보행 단계 (gait phase) 및 보행 주기(gait cycle)의 견관절 각도(Figure 5), 지면에 대한 체간의 각도(Figure 6), 힘의 작용점에서부터 대전자까

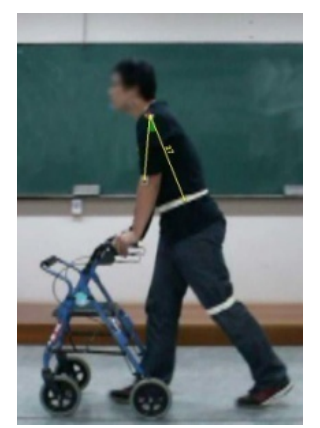

Figure 5. Angle of the shoulder

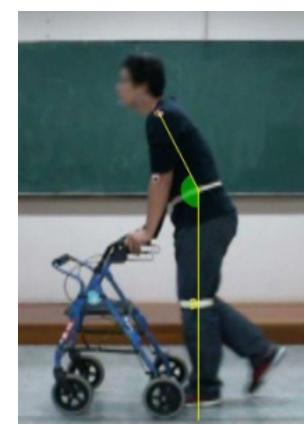

Figure 6. Angle between the body trunk and the ground



Figure 7. Distance between the point of action and the greater trochanter 
지 거리(Figure 7)를 측정하였다.

한 보행 주기당 보행 단계는 보행 시작 시 두 발이 지면에 지지하고 있는 (1)초기 양하지 접지기, 보행을 시작하여 한 발이 지면에 지지하고 있고, 다른 한 발은 swing하고 있는 (즉, 한 발은 입각기 상태, 다른 한 발은 유각기 상태) (2)단 하지 지지기, 발의 위치가 초기 양하지 접지기와 반대가 되 는 (3) 말기 양하지 접지기, 발의 위치가 단하지 지지기와 반 대가 되는(즉, 한 발은 유각기 상태, 다른 한 발은 입각기 상태) (4) 유각기, 그리고 다시 발이 보행 시작 시의 위치와 동일하게 되는 (5)양하지 지지기로 정의하여 분석하였다 (Jung, et al., 2006).

피실험자는 총 5 주기의 보행을 하였고, 본 실험에서는 1 주기와 5 주기의 보행 주기를 제외한 중간의 3 주기에 대하 여 분석을 실시하였다. 1 주기당 5 단계의 보행을 초당 30 프 레임의 화면으로 나누어 견관절 각도와 지면에 대한 체간의 각도 및 힘의 작용점에서부터 대전자까지 거리를 측정한 후 각 단계의 평균값 및 전체 주기의 평균값을 산출하였다.

\subsection{Statistics method}

본 연구를 통해 수집된 자료는 SPSS 15.0을 이용하여 분석하였다. 연구대상자의 일반적 특성은 기술통계를 사용하 였으며, 연구대상자의 수가 많지 않은 관계로 여타 실험 결 과에 대한 분석은 비모수검정을 실시하였다. 보행보조차와 유모차 사용시 각각의 견관절 각도와 지면에 대한 체간의 각 도 비교 및 힘의 작용점에서부터 대전자까지 거리 비교는 윌콕슨 부호순위검정 (Wilcoxon signed ranks test)을 사용 하여 분석하였다. 통계 처리의 통계적 유의 수준은 0.05로 하였다.

\section{Result}

\subsection{Structure analysis of the outdoor rollator and the bassinet}

\subsubsection{Structure analysis of the outdoor rollator}

보행보조차의 무게는 $10.5 \mathrm{~kg}$ 이고, 구조를 지지하는 각 프 레임의 길이는 기 $58 \mathrm{~cm}$, ᄂ이 $63 \mathrm{~cm}$, 디 $27 \mathrm{~cm}$, 리이 $17 \mathrm{~cm}$ 이고, 각 프레임이 이루는 각은 $\mathrm{A}$ 가 $60^{\circ}$ 이다(Figure 8) (Table 2). 보행보조차는 힘의 작용점인 손잡이가 회전축 이 되는 양쪽 바퀴의 사이에 위치하고 있다. 이러한 이유로 보행보조차는 구조역학적으로 손잡이에 가해지는 수직힘을 통해 구조물의 구조안정성이 무너져 균형을 잃을 가능성은 없다. 즉 보행보조차의 손잡이나 프레임이 파괴되어, 구조물
의 형태나 힘의 작용점 위치가 변화하지 않는 이상 보행보조 차는 구조안정성을 유지한다.

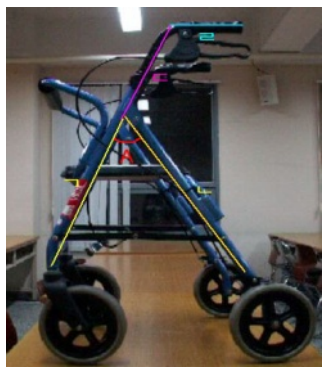

Figure 8. Structure of the outdoor rollator

Table 2. Structure of the outdoor rollator(q.v. Figure 8)

\begin{tabular}{c|c}
\hline & Outdoor rollator \\
\hline Weight $(\mathrm{kg}$ & 10.5 \\
\hline Length $(\mathrm{cm})$ & ᄀ: 58, ᄂ: 63, ᄃ: $: 27$, ᄅ: 17 \\
\hline Angle $\left({ }^{\circ}\right)$ & A: 60 \\
\hline
\end{tabular}

\subsubsection{Stucture analysis of the bassinet}

유모차의 무게는 $10.1 \mathrm{~kg}$ 이고, 구조를 지지하는 각 프레 임의 길이는 기이 $55 \mathrm{~cm}$, ᄂ이 $18 \mathrm{~cm}$, 디 $22 \mathrm{~cm}$, 리이 $52 \mathrm{~cm}$, 미이 $61 \mathrm{~cm}$, 비이 $42 \mathrm{~cm}$ 이고, 각 프레임이 이루는 각 은 a가 $57^{\circ}, \mathrm{b}$ 가 $58^{\circ}, \mathrm{c}$ 가 $73^{\circ}, \mathrm{d}$ 가 $50^{\circ}$, e가 $65^{\circ}, \mathrm{f}$ 가 $65^{\circ}$ 이 다(Figure 9) (Table 3).

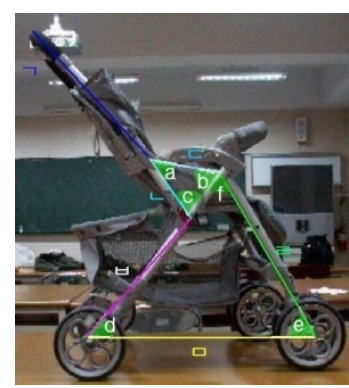

Figure 9. Structure of the bassinet

Table 3. Structure of the bassinet(q.v. Figure 9)

\begin{tabular}{c|c}
\hline & Bassinet \\
\hline Weight $(\mathrm{kg})$ & 10.1 \\
\hline Length $(\mathrm{cm})$ & ᄀ: 55, ᄂ: 18, ᄃ: 22, ᄅ: 52, 口: 61, ㅂ: 42 \\
\hline Angle $\left(^{\circ}\right)$ & a: 60, b: 58, c: 73, d: 50, e: 65, f: 65 \\
\hline
\end{tabular}


유모차의 구조분석에는 다음과 같은 식이 사용된다.

$M x$ : 유모차의 손잡이에 가해지는 전체 수직힘

$M_{A}$ : 유모차의 뒷바퀴에 가해지는 힘

$M_{B}$ : 유모차의 앞바퀴에 가해지는 힘

$R_{B}$ : 유모차의 뒷바퀴를 축으로 유모차의 앞바퀴가 상 방회전하는 힘

$M x=\left(73 \cos 57^{\circ}-42 \cos 50^{\circ}\right) \times x$

$M_{B}=R_{B} \times 61$

유모차 손잡이에 수직힘이 가해지지 않았을 경우, 유모 차의 무게인 $10.1 \mathrm{~kg}$ 가 프레임의 길이 비율에 따라 앞바퀴 $\left(M_{B}\right)$ 에 $4 \mathrm{~kg}$, 뒷바퀴 $\left(M_{A}\right)$ 에 $6.1 \mathrm{~kg}$ 의 하중이 분산되게 된 다. 이에 따라,

$$
\begin{aligned}
& R_{B}=4-0.0216 x \\
& M_{B}=(4-0.0216 x) \times 61
\end{aligned}
$$

이라는 식이 성립한다. 프레임의 변형이나 힘의 작용점 이 동과 같은 구조물의 변화가 일어나지 않은 채 유모차의 구조 안정성이 무너지려면, 즉 유모차가 손잡이에 가해진 수직힘 으로 인해, 뒷바퀴를 회전축으로 앞바퀴가 상방으로 회전하 여 구조물이 균형을 잃으려면 $M x>M_{B}$ 가 되어야 한다. 이 에 따라,

$$
\begin{aligned}
& M x>M_{B} \\
& \left(73 \cos 57^{\circ}-42 \cos 50^{\circ}\right) \times x>(4-0.0216 x) \times 61 \\
& 12.7615 x>244-1.3176 x
\end{aligned}
$$$$
x>17.33
$$

이 된다. 즉, $17.33 \mathrm{~kg}$ 을 초과하는 수직힘이 유모차의 손잡 이에 가해진다면, 지렛대의 원리에 의해 앞바퀴가 상방으로 회전하면서 지면과 떨어지게 되어 구조안정성을 상실하게 된다.

\subsection{Angle of the shoulder - gate phase}

보행 단계 중 5 가지 모든 단계에서 통계적으로 유의한 차이가 있었으며, 보행보조차를 사용할 때보다 유모차를 사 용할 때 견관절 각도가 더 크게 나타났다(Table 4).

\subsection{Angle of the shoulder - gate cycle}

\begin{tabular}{|c|c|c|c|c|}
\hline & Outdoor rollator & Bassinet & $\mathrm{Z}$ & $p$ \\
\hline $\begin{array}{l}\text { Initial double } \\
\text { limb stance }\end{array}$ & $18.38 \pm 24.22$ & $32.15 \pm 18.62$ & -3.063 & $0.002^{*}$ \\
\hline $\begin{array}{l}\text { Single limb } \\
\text { support }\end{array}$ & $18.31 \pm 24.28$ & $31.54 \pm 18.64$ & -3.116 & $0.002^{*}$ \\
\hline $\begin{array}{c}\text { Terminal double } \\
\text { limb stance }\end{array}$ & $18.46 \pm 24.77$ & $31.46 \pm 18.01$ & -3.061 & $0.002^{*}$ \\
\hline Swing & $18.31 \pm 24.69$ & $32.46 \pm 18.36$ & -3.008 & $0.003^{*}$ \\
\hline $\begin{array}{l}\text { Double limb } \\
\text { stance }\end{array}$ & $18.54 \pm 25.18$ & $32.31 \pm 18.70$ & -2.971 & $0.003^{*}$ \\
\hline
\end{tabular}

보행 주기별 보행보조차와 유모차 사용 시 견관절의 각도
측정 결과, 보행보조차는 평균 $18.40^{\circ} \pm 24.59$, 유모차는 평균 $31.98^{\circ} \pm 18.42$ 로 유의한 차이가 있었다(Table 5).

Table 4. Angle of the shoulder - gate phase $\left({ }^{\circ}\right)$

Table 5. Angle of the shoulder - gate $\operatorname{cycle}\left(^{\circ}\right)$

\begin{tabular}{c|c|c|c}
\hline & Average & $Z$ & $p$ \\
\hline Outdoor rollator & $18.40 \pm 24.59$ & \multirow{2}{*}{-3.076} & \multirow{2}{*}{$0.002^{*}$} \\
\cline { 1 - 2 } Bassinet & $31.98 \pm 18.42$ & & \\
\hline${ }^{*} p<0.05$ &
\end{tabular}

\subsection{Angle between the body trunk and the ground - gate phase}

보행 단계 중 5 가지 모든 단계에서 체간의 각도는 보행 보조차를 사용할 때와 유모차를 사용할 때, 통계적으로 유의 한 차이를 보이지 않았다(Table 6).

Table 6. Angle between the body trunk and the ground - gate phase $\left(^{\circ}\right)$

\begin{tabular}{c|c|c|c|c}
\hline & Outdoor rollator & Bassinet & $\mathrm{Z}$ & $\mathrm{p}$ \\
\hline $\begin{array}{c}\text { Initial double } \\
\text { limb stance }\end{array}$ & $162.54 \pm 7.46$ & $164.38 \pm 7.69$ & -1.261 & 0.207 \\
\hline $\begin{array}{c}\text { Single limb } \\
\text { support }\end{array}$ & $161.38 \pm 7.57$ & $163.69 \pm 7.10$ & -1.875 & 0.061 \\
\hline $\begin{array}{c}\text { Terminal double } \\
\text { limb stance }\end{array}$ & $162.54 \pm 7.69$ & $164.08 \pm 7.39$ & -1.382 & 0.167 \\
\hline Swing & $162.23 \pm 8.08$ & $163.15 \pm 7.80$ & -0.878 & 0.380 \\
\hline $\begin{array}{c}\text { Double limb } \\
\text { stance }\end{array}$ & $164.00 \pm 7.96$ & $164.54 \pm 7.42$ & -0.394 & 0.693 \\
\hline${ }^{*} p<0.05$ & & &
\end{tabular}




\subsection{Angle between the body trunk and the ground - gate cycle}

보행 주기별 보행보조차와 유모차 사용 시 지면에 대한 체 간의 각도 측정 결과, 보행보조차는 평균 $162.54^{\circ} \pm 7.61$, 유모차는 평균 $163.97^{\circ} \pm 7.32$ 로 유의한 차이가 없었다 (Table 7).

Table 7. Angle between the body trunk and the ground - gate cycle $\left({ }^{\circ}\right)$

\begin{tabular}{c|c|r|c}
\hline & Average & $\mathrm{Z}$ & $\mathrm{p}$ \\
\hline Outdoor rollator & $162.54 \pm 7.61$ & \multirow{2}{*}{-1.258} & 0.208 \\
\cline { 1 - 2 } Bassinet & $163.97 \pm 7.32$ & & \\
\hline${ }^{*} p<0.05$ & \multicolumn{3}{|l}{}
\end{tabular}

\subsection{Distance between the point of action and the greater trochanter - gate phase}

보행 단계 중 5 가지 모든 단계에서 통계적으로 유의한 차이가 있었으며, 보행보조차를 사용할 때보다 유모차를 사 용할 때 힘의 작용점에서 대전자까지의 거리가 더 크게 나 타났다(Table 8).

Table 8. Distance between the point of action and the greater trochanter - gate phase $(\mathrm{cm})$

\begin{tabular}{c|c|c|c|c}
\hline & Outdoor rollator & Bassinet & $\mathrm{Z}$ & $p$ \\
\hline $\begin{array}{c}\text { Initial double } \\
\text { limb stance }\end{array}$ & $33.62 \pm 15.85$ & $42.69 \pm 11.86$ & -2.831 & $0.005^{*}$ \\
\hline $\begin{array}{c}\text { Single limb } \\
\text { support }\end{array}$ & $34.39 \pm 16.12$ & $43.54 \pm 12.36$ & -2.844 & $0.005^{*}$ \\
\hline $\begin{array}{c}\text { Terminal double } \\
\text { limb stance }\end{array}$ & $33.23 \pm 16.47$ & $43.15 \pm 12.67$ & -3.062 & $0.002^{*}$ \\
\hline Swing & $33.69 \pm 15.85$ & $44.38 \pm 12.67$ & -3.182 & $0.001^{*}$ \\
\hline $\begin{array}{c}\text { Double limb } \\
\text { stance }\end{array}$ & $33.00 \pm 15.13$ & $43.77 \pm 12.92$ & -3.186 & $0.001^{*}$ \\
\hline${ }^{*} p<0.05$ & & &
\end{tabular}

\subsection{Distance between the point of action and the greater trochanter - gate cycle}

보행 주기별 보행보조차와 유모차 사용 시 힘의 작용점에 서부터 대전자까지 거리변화 측정 결과, 보행보조차는 평균 $33.58 \pm 15.83 \mathrm{~cm}$, 유모차는 평균 $43.51 \pm 12.40 \mathrm{~cm}$ 으로 유 의한 차이가 있었다(Table 9).
Table 9. Distance between the point of action and the greater trochanter - gate cycle $(\mathrm{cm})$

\begin{tabular}{c|c|c|c}
\hline & Average & $\mathrm{Z}$ & $p$ \\
\hline Outdoor rollator & $33.58 \pm 15.83$ & \multirow{2}{*}{-6.679} & $0.000^{*}$ \\
\cline { 1 - 2 } Bassinet & $43.51 \pm 12.40$ & & \\
\hline${ }^{*} p<0.05$ & &
\end{tabular}

\section{Discussion}

보행은 인간활동의 기본이 되는 요소로, 신체가 어떠한 장소에서 다른 곳으로 움직이는 것을 말한다(Jung, et al., 2006). 또한 안정성을 유지하면서 하지를 반복적으로 움직 여 신체를 움직이는, 모든 체간과 하지의 여러 분절 사이에 서 이루어지는 연속적 상호작용을 의미한다(Prince, et al., 1997).

이러한 보행 동작이 이루어지기 위해서는 자세 조절과 균형이 필수적이다. 또한 사지 및 체간의 충분한 근력이 필 요하다(Izquierdo, et al., 2008). 자세 조절이란 공간에서 신체의 무게 중심을 유지하는 능력을 의미하며 (Kim and $\mathrm{Han}, 2002)$, 균형은 정지해 있거나 움직이는 지지 기저면 (base of support; BOS)에 대해 스스로가 몸의 무게 중심 (center of mass; COM)을 제어하는 과정으로 정의된다 (Debra, 2003). 더 나아가 자세조절과 균형은 몸을 불안 정성 상태에서 다시 회복하는 능력뿐만 아니라 다양한 방 법을 이용하여 불안정성을 피하도록 예측하고 움직여 안정 성을 유지하는 능력까지 포함한다(Shumway-Cook, et al., 1997).

Koozerkanani, et al.(1980)에 따르면 보행시 안정성을 가지기 위해서는 지지 기저면(base of support)내에 사용 자의 보행 압력 중심(center of pressure)이 위치하여야 한다. 또한 안전성은 기저면 내에 중력선 존재 유무와 중력 중심(center of gravity) 높이, 기저면의 넓이에 영향을 받으 며, 기저면의 넓이가 확장될수록 안정성을 획득하는데 도움 이 된다고 하였다(Galley, \& Forster, 1987; Kaminisk, \& Simpkins, 2001; Laura, et al., 1996) . 하지만 노화가 진행 되면서 다양한 요인들로 인해 보행속도(velocity) 및 보장 (step length)의 감소 등의 보행 패턴 변화가 발생하게 되고, 이로 인해 안정성이 저하되게 된다(Alexander, 1996). 이 러한 노인의 보행 문제에 대한 중재로 보행보조도구의 사용 이 이루어진다.

지팡이를 이용한 보행시에 대한 체중지지 분포에 대한 연 구에 따르면 지팡이를 사용할 때 평균적으로 전체 체중의 
$15 \%$ 에서 $40 \%$ 의 체중이 지팡이에 지지된다고 보고하였다 (Ely and Smidt, 1977). 또한 지팡이를 사용할 때의 지지 기저면은 일반 보행시보다 약 1.5 배 증가한다는 연구가 있 다(Jebsen, 1967). 보행보조차에 대한 연구에서도 보행보 조차가 사용자의 지지 기저면 확대 및 체중지지에 이득이 있다고 보고되었다. Alkjaer, et al.(2006)의 연구에 따르면, 보행보조차를 이용해 걸을 때, 무릎 신전근을 비롯한 하지근 육의 체중부하를 줄여주고, 고관절의 관절가동범위를 확장시 키며, 보행 지지 기저면의 확대가 이루어진다. 최근에는 보 행보조기와 인간공학을 결부시켜 안정성과 효과성을 증진시 킨 보행보조차의 새로운 디자인에 대한 연구가 확대되고 있 다. 보행보조차의 핸들 및 스톱퍼 구조 개선이나, 사용자들 의 신체에 맞춘 표준형 보행보조기에 대한 연구가 활발히 진행되고 있다(Shin, et al., 2008; Hwang, 2006).

하지만 이러한 보행보조도구가 사용자에게 충분한 기능을 제공하지 못하거나, 사용상의 안전 문제 및 근골격계상의 변 형을 초래한다면 이는 매우 큰 문제이다. 이러한 이유로 현 재 보행보조용으로 많이 사용되고 있는 유모차에 대한 안정 성 및 효과성에 대한 연구가 필요하다.

본 연구는 보행보조차와 유모차를 보행보조도구로 사용하 였을 때 나타나는 신체분절의 각도와 힘점과 사용자와의 거 리를 측정하여, 각각의 차이를 규명하는 연구이다. 실험 결 과에 따르면 유모차를 사용한 보행 시 보행보조차보다 견관 절의 각도가 더 컸으며, 지면에 대한 체간의 각도는 유의한 차이를 볼 수 없었다. 반면에 힘의 작용점과 사용자의 대전 자간 거리는 유모차가 보행보조차보다 더 멀었다.

체간의 각도가 차이가 없었음에도 불구하고, 힘의 작용점 에서 대전자간의 거리와 피실험자의 견관절 각도에 위와 같 은 차이가 있다는 것은 유모차를 사용하는 경우 피실험자와 보행보조도구간의 거리가 보행보조차를 사용하였을 때 보다 더 멀었음을 의미한다. 이는 보행보조차를 사용할 경우 사 용자의 무게 중심이 보행보조차의 지지 기저면 내에 있거나 상대적으로 지지 기저면에 근접해 위치한다는 Bohannon (1997)의 연구로 미루어 보아 유모차가 보행보조의 역할에 상대적으로 적합하지 않다는 것을 의미한다. 또한 견관절 각 도의 차이를 통해, 유모차와 보행보조차를 사용할 경우 상지 를 통해 가해지는 힘의 방향이 유의하게 다르다는 것을 알 수 있다. 이를 힘의 벡터 합성 개념에 대입해 볼 때 보행보 조차를 사용하는 경우 상지에서 가해지는 힘의 방향이 유모 차를 사용할 때 보다 인체의 중력선에 더 가까워지게 되고, 상지에서 수직으로 체중보조를 위해 작용하는 힘의 크기도 더 커지기 때문에 체중지지의 이점이 있다고 볼 수 있다. 또 한 보행보조차와 유모차의 구조역학적 분석에 따르면 유모 차가 지지할 수 있는 외력이 보행보조차의 그것보다 더 작 기 때문에 이 역시 사용자의 체중지지를 제한하고, 사용자의
안전을 저해시키는 요인이라 생각할 수 있다. 이러한 점들이 보행보조차와 유모차의 안정성 및 효과성에 대한 차후 연구 에 기초 자료가 될 수 있을 것이며, 이에 본 연구의 의의가 있을 것이라 생각된다.

하지만 본 연구에서는 실험환경 및 측정 도구의 한계로 인 해 피실험자의 무게 중심 변화와 지지 기저면의 변화 및 피 실험자가 보행보조도구에 가하는 힘의 크기에 대한 실험을 하지 못하였다. 이 때문에 각 보행보조도구의 사용으로 획득 되는 체중지지 및 균형능력 증진에 대한 수치적, 통계적 분 석에 한계가 있었다. 또한 대상 선정의 측면에서 실제 보행 보조도구 사용자를 대상으로 한 실험이 아닌, 보행보조도구 를 사용하지 않는 정상인을 대상으로 하였기에 사용패턴에 대한 정확한 분석이 어려웠고, 실험대상자의 수가 많지 않아 서 결과를 일반화시키기에 부족하였다. 또한 보행보조차의 재료역학분석을 하지 않아 보행보조차 각 재질의 강도를 알 수 없었고, 이런 이유로 보행보조차의 구조안정성이 파괴되 는 최대 부하를 측정하지 못하였다. 이 밖에도 실험도구인 유모차에 대한 선행 연구나 일반화된 자료 및 기술표준이 부 족하였다.

앞으로의 연구에서는 $3 \mathrm{D}$ 동작분석을 통한 3 차원 좌표 측 정 및 압력측정판을 사용한 힘의 측정을 통해 보행보조도구 의 안정성에 대한 심도있고 폭 넓은 연구가 필요할 것이다. 또한 실제 보행보조도구 사용자를 대상으로 한 연구가 진행 되어야 하며, 유모차를 보행보조도구로 사용할 때 발생할 수 있는 문제에 대한 사회학적, 인간공학적, 생체역학적 분석 및 대안제시가 이루어져야 할 것이다.

\section{Conclusion}

본 연구는 보행보조차와 유모차를 사용하였을 때 나타나 는 신체분절의 각도와 힘의 작용점과 사용자와의 거리를 측 정하여, 각각의 차이를 규명하는 연구이다. 보행보조차와 유 모차의 구조분석 결과 상대적으로 유모차보다 보행보조차의 구조안전성이 높았으며, 정상인을 대상으로 한 보행분석 결 과 상지의 견관절 각도가 유의하게 차이를 보였고, 지면에 대한 체간의 각도는 유의한 차이가 없었다. 힘의 작용점과 대전자와의 거리에서는 쌍방간의 유의한 차이를 보였다.

유모차 보행 시 견관절 각도가 더 컸고, 대전자와 힘의 작 용점과의 거리는 더 멀었다. 이는 유모차가 보행보조차보다 보행보조도구와 사용자간의 거리가 더 멀고 보행보조도구에 작용하는 힘의 방향이 달랐기 때문에, 유모차가 체중지지에 서도 더 불리하였음을 추정할 수 있다. 이는 유모차를 보행 보조도구로 사용할 경우 보행보조차보다 안정성과 효과성이 


\section{낮다고 생각할 수 있다. \\ 이와 같이 본 연구를 통해 국내에서 연구가 전무했던 보행 보조차 및 유모차를 이용한 보행의 기초 자료를 제시하였고, 보행보조도구의 구조분석을 통해 유모차의 안정성 문제를 밝혔다. 이를 통해 보행보조도구의 역할로 유모차를 사용하 는 것의 안정성 문제를 환기시킬 수 있었다는 것이 본 연구 의 의의이다.}

\section{References}

Alexander, N. B., Gait Disorders in Older Adults, Journal of the American Geriatrics Society, 44(4), 434-451, 1996.

Alkjaer, T., Larsen, P. K., Pedersen, G., Nielsen, L. H. and Simonsen, E. B., Biomechanical analysis of rollator walking, BioMedical Engineering OnLine, 5(2), 2-9, 2006.

Anniansson, A., Herdberg, M., Henning, G. and Grimby, G., Muscle morphology, enzymatic activity and muscle strength in the elderly men: A follow-up study, Muscle Nerve, 9(7), 585-591, 1986.

Berg, K. O., Wood-Dauphinee, S. L., Williams J. I. and Maki, B., Measuring balance in the elderly: Validation of an instrument, Canadian Journal of Public Health, 83(2), 7-11, 1992

Berg, K. O., Wood-Dauphinee, S. L. and Williams, J. I., The balance scale: Reliability assessm-ent with elderly residents and patients with an acute stroke, Scandinavian Journal of Rehabilitation Medicine, 27(1), 27-36, 1995.

Bohannon, R. W., Gait performance with wheeled and standard walkers, Perception and Motor Skills, 85(2), 1185-1186, 1997.

Brandt, A., Iwarsson, S. and Stahl, A., Satisfaction with rollators among community-living users: a follow-up study, Disability \& Rehabilitation, 26(7), 343-353, 2003.

Cho, H. B., Entered the aging society in the sports industry prospects and problem, Journal of sport science research, 26(0), 79-92, 2008.

Debra, J. R., Fall proof, A comprehensive balance and mobility training program, Champaign: Human Kinetics, 2003.

Ely, D. D. and Smidt, G. L., Effect of cane on variables of gait for patients with hip disorders, Physical Therapy, 57(5), 507-512, 1977.

Eom, J. J., Used-bassinets "Goods for elderly people". Maeil News, 2005. 06. 03 .

Finkel, J., Fernie, G. and Cleghorn, W., A guideline for the design of a four-wheeled walker, Assist Technology, 9(2), 116-129, 1997.

Galley, P. M. and Forster, A. L., Human movement: An introductory text for physiotherapy students. Churchill Livingstone, 1987.

Guralink, J. M. and Kaplan, G. A., Predictor of healthy aging: Prospective evidence from the Alameda country study, American Journal of Public Health, 79(6), 703-708, 1989.

Hwang, K. C., A Practical Design of the Efficient Walking Aids, Hongik University, Master's thesis, 2006.

Izquierdo, M., Martinez-Ramirez, A., Larriin, J. L., Irujo-Espinosa, M. and
Gomez, M., Functional capacity evaluation in a clinical and ambulatory setting: new challenges of accelerometry to assessment balance and muscle power in aging population, Anales del sistema sanitario de Navarra, 31(2), 159-170, 2008.

Jebsen, R. H., Use and abuse of ambulation aids, Journal of the American Medical Association, 199(1), 5-10, 1967.

Jung, I. G., Used-bassinets recycling campaigns, The Jeju Daily News, 2006. 08. 18 .

Jung, S., et al. Gate Analysis. Youngmun Publishing Company, 2006.

Kaminisk, T. R. and Simpkins, S., The effects of stance configuration and target distance on reaching. I. Movement preparation, Experimental brain research, 136(4), 439-446, 2001.

Kauffman, T. L., Geriatric Rehabilitation Manual, Churchill Livingstone, 1999.

Kim, S. J. and Han, D. W., The Study of Development Control Strategy in Postural Maintenance, The Korean Journal of Physical Education, 41(5), 827-836, 2002

Kim, T. S., Scarcity of the used-bassinets, $M B C$ News, 2007. 08. 27.

Koozerkanani, S. H., Stockwell, C. W., McGhee, R. B. and Firoozmand, F., On the role of dynamic models in quantitative posturography, IEEE Transactions on Biomedical Engineering, 27(10), 605-609, 1980.

Korean Agency for Technology and Standards. Self-Regulatory Safety Confirmation System - Walking Aids for Elderly People. Ministry of Knowledge Economy, R. O. Korea, 2007.

Laura, K. S., Elizabeth, L. W. and Lehmkuhl, L. D., Brunnstrom's Clinical Kinesiology, Davis, F.A. 1996.

Lee, J. K., Grandmother said "Where is the used-bassinet?", Segye Times, 2007. 11.16

Lewis, C. and Bottomley, J., Musculoskeletal changes with age. In: Lewis, C., (Ed.), Aging: The health care's challenge. (4th ed.), Davis, F.A., Philadelphia, 2002

Park, J. Y. and Cho, A., "A Safety evaluation of Walking Aids for the aged", Spring Conference of Ergonomics Society of Korea, 3 (pp. 23-27), Gumi, Gyeongbuk, 2008

Prince, F., Corriveau, H., Hebert, R. and Winter, D. A., Gait in the elderly, Gait and Posture, 5(2), 128-135, 1997.

Samuelsson, K. and Wressle, E., User satisfaction with mobility assistive devices: An important element in the rehabilitation process, Disability \& Rehabilitation, 30(7), 551-558, 2008.

Shin, D. J., et al. "Design Improvement and Anthropometric Analysis of Four-wheeled Walker", Fall Conference of Ergonomics Society of Korea, 4 (pp. 12-13), Gimhae, Gyeongnam, 2008.

Shumway-Cook, A., Woollacott, M., Kerns, K. A. and Baldwin, M., The effects of two types of cognitive tasks on postural stability in older adults with and without a history of falls, Journals of Gerontology Series A: Biological Sciences and Medical Sciences, 52(4), 232-240, 1997.

Smidt, G. L. and Mommens, M. A., System of Reporting and Comparing Influence of Ambulatory Aids on Gait, Physical Therapy, 60(5), 551 $-558,1980$.

Spirduso, W. W., Francis, K., Eakin, T. and Stanford, C., Quantification of manual force control and tremor, Journal of Motor Behavior, 37(3), 
$197-210,2005$

Statistics Korea, 2008 Aged People Statistics, Statistics Korea, 2008.

Yang, Y. A., et al. Occupational Therapy for Elderly People, Gye-Chuk, 2008.

\section{Author listings}

Min Su Park: aftermath67@naver.com

Highest degree: B.O.T, Department of Occupational Therapy, Inje University

Position title: Student, Studying for Master's degree, Department of Occupational Therapy, Inje University

Areas of interest: Musculoskeletal Disease, Universal Design
Soo Hee Park: p334005@honam.ac.kr

Highest degree: M.O.T. Department of Occupational Therapy, Inje University

Position title: Professor, Department of Occupational Therapy, Honam University

Areas of interest: Occupational Therapy, Ergonomics

Yeong Ae Yang: otyya62@inje.ac.kr

Highest degree: $\mathrm{PhD}$, Department of Occupational \& Environment Medicine, Hanyang University

Position title: Professor, Department of Occupational Therapy, College of Biomedical Sciences and Engeneering, Inje University

Areas of interest: Occupatioanl Therapy, Environment Medicine

Date Received : 2010-01-11

Date Revised : 2012-02-07

Date Accepted : 2012-02-28 